\title{
GIS-Based Preliminary Seismic Hazard Identification and Assessment of National Bridges in the Greater Manila Region Covered by the West Valley Fault
}

\author{
George Mariano A. Soriano ${ }^{1 \& 2}$, Djon Mar Ellyz M. Santiago ${ }^{1 \& 3}$ and Anthony B. Medina Jr. ${ }^{1}$
}

\begin{abstract}
The paper discussed the GIS-based identification of seismically vulnerable bridges within $5-10 \mathrm{~km}$ of the West Valley Fault. The assessment was conducted by integrating the bridge information in the Road and Bridge Inventory Application, the borehole data from the Geotechnical Database System, and the West Valley Fault Data, as well as Spectral Acceleration Maps from the Bridge Seismic Design Specification of the Department of Public Works and Highways. Outputs produced by this paper include the Hazard Ranking Table and the Design Response Spectra.
\end{abstract}

Keywords-Seismic, GIS, Hazard, Bridge, Assessment, PGA, Response Spectra.

\section{INTRODUCTION}

According to the Valley Fault System Atlas produced by the Philippine Institute of Volcanology and Seismology (PHIVOLCS) and the National Disaster Risk Reduction and Management Council (NDRRMC), the West Valley Vault (WVF) is a 100-kilometer active fault transecting the cities of Quezon City, Marikina, Pasig, Muntinlupa, and Taguig. Moreover, the fault also extends to neighbouring provinces of Bulacan, Rizal, Laguna, and Cavite. The projection of the West Valley Fault can be seen in Figure 1.

As predicted by PHIVOLCS, the WVF is capable of producing a 7.2 magnitude earthquake equivalent to life and property damage rated at Intensity VIII in the PHIVOLCS Earthquake Intensity Scale (PEIS) for Metro Manila and aforementioned provinces. Consequently, as the political and economic capital of the country, massive seismic damage in the Greater Manila region is detrimental to the fate of the country as a whole.

The Department of Public Works and Highways (DPWH), as the primary engineering and construction arm of the Government of the Philippines (GOP), is mandated to oversee the design and construction of quality and safe public infrastructure. In the joint effort of the Japan International Cooperation Agency (JICA), the Metro Manila Development

\footnotetext{
${ }^{1}$ Engineer, Bureau of Design, Department of Public Works and Highways, Republic of the Philippines

${ }^{2}$ Faculty, School of Civil, Environmental, Sanitary, \& Geological Engineering, Mapua Institute of Technology, Republic of the Philippines

${ }^{3}$ Graduate Student, School of Civil, Environmental, Sanitary, \& Geological Engineering, Mapua Institute of Technology, Republic of the Philippines
}

Authority (MMDA), and PHIVOLCS, an Earthquake Impact Reduction Study for Metro Manila was formulated in 2004. Under the USI-5 and USI-6 of the disaster response framework, the master plan formulation aims to promote earthquake resistant public facilities and promote earthquake resistant infrastructure. In this regard, the DPWH is then tasked to oversee that these objectives are met.

Western Valley Fault Shapefile

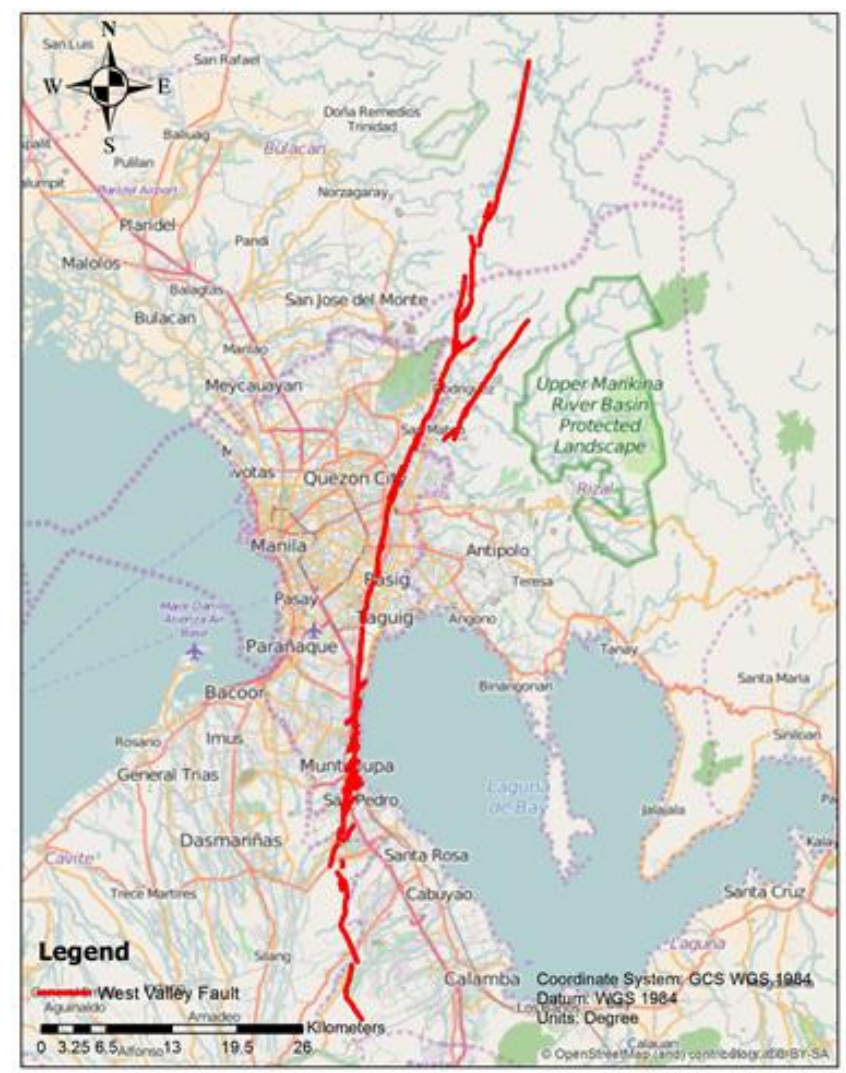

\section{II.FRAMEWORK AND OBJECTIVES OF THE STUDY}

In this study, the focus will revolve around the seismic hazard identification and assessment of existing national bridges within the Greater Manila Area. The study intends to utilize the GIS capabilities of the Department in integrating various independent databases and undertake geospatial analysis, response spectrum analysis, and hazard ranking from 
the combined data. Figure 2 presents a simple flowchart of this study.

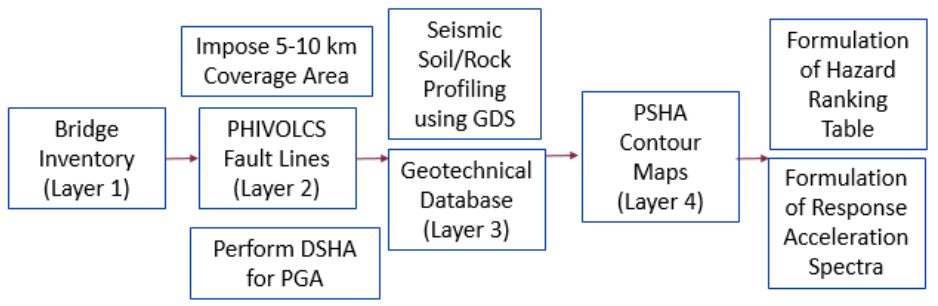

Fig. 2: Flowchart of the Study

Since bridges are the weakest link in the national road network, it is crucial that existing bridges can withstand the earthquake forces should the occasion arises. Old bridges that were constructed before the formulation of modern seismic code requirements are particularly vulnerable due to their old age and design limitation. Hence, the results of this study are intended to address the following objectives stated below.

- Identify national bridges within 5-10 kilometers of the West Valley Fault and rank their vulnerabilities using Peak Ground Acceleration (PGA), Bridge Condition, and Bridge Length as ranking criteria.

- Produce different response spectra based on the National Structural Code of the Philippines, the Japan Road Association Guideline, and a Hybrid Spectra produced from Deterministic Seismic Hazard Analysis (DSHA).

- Recommend to higher policy institutions priority bridges for rapid response by providing technical basis for budgeting.

- Provide technical data for retrofitting works of old bridges by undertaking response spectra analysis.

In this particular paper, the first two objectives can be conclusively achieved. On the other hand, the last two objectives will take further refinement of this process since a deeper coordination with the concerned personnel inside and outside the Department will still have to be consulted. Furthermore, since this method of GIS assessment is new, it will take additional review and cascading to institutionalize this practice.

\section{Methodology}

As stated in the framework, the study will be conducted by integrating various databases into one GIS layer. In this section, the databases will be discussed in detail. The geospatial analysis and response spectra specifications will also be discussed briefly

\section{A. Road and Bridge Inventory Application (RBIA)}

Please submit your manuscript electronically for review as e-mail attachments. When you submit your initial full paper version, prepare it in two-column format, including figures and tables.
B. West Valley Fault Shape File and Direct Seismic Hazard Analysis (DSHA)

The Shape File of the West Valley Fault was requested from PHIVOLCS. The WVF shape file will be used to determine the proximity of national bridges in order to conduct Direct Seismic Hazard Analysis and produce the predicted Peak Ground Acceleration using the Fukushima and Tanaka (1990) attenuation equation as prescribed by the DPWH Design Guidelines, Criteria, and Standards 2015 Vol. 2A. $\log A=0.41 M-\log \left(R+0.032 \times 10^{0.4 M}\right)-0.0034 R+1.3$

(1)

In this equation two parameters are needed, the nearest distance of a site to a point in the fault line and the maximum surface wave magnitude the fault can produce. The site distance to fault $R$ is given in kilometres while the Peak Ground Acceleration $A$ is given in $\mathrm{cm} / \mathrm{s}^{2}$. In order to determine the nearest distance of a specific bridge to the fault line, the "near" function in the ArcGIS was used. Figure 3 shows the concept of the near function in ArcGIS.

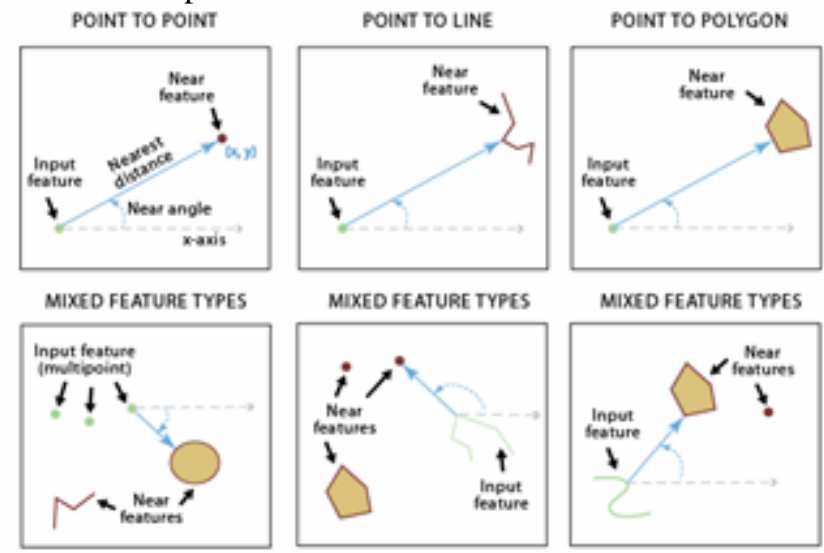

Fig. 3: Diagram of the Near Function as described in ArcGIS Online

\section{Geotechnical Database System (GDS)}

The Geotechnical Database System is a pioneer project of the Surveys and Investigation Division of the DPWH that aims to consolidate borehole logs from previous geotechnical investigations of DPWH infrastructure projects. The aim of this database is to provide a more detailed soil profile than readily present soil profile maps. The soil profiles herein collated can provide a better approximation of the soil profile for a particular bridge, which in turn will aid in the formulation of the bridge's design response spectra. Figure 4 shows a sample result of the GDS. 
Identify from: <Top-most layer>

曰-SDE.GISADMIN.Borehole_Logs

Proposed C-5/FTI Access Ramps to Skyway Improvement Project

\begin{tabular}{|c|c|}
\hline Location: & 121.05105314 .517908 Decimal Degrees \\
\hline Field & Value \\
\hline OBJECTID & 245 \\
\hline Project_Na & Proposed C-5/FTI Access Ramps to Skyway Improvement Proje \\
\hline Project_Co & BH 35 \\
\hline Region & NCR \\
\hline Province & Metro Manila \\
\hline Project_Lo & Taguig City \\
\hline Testing_La & J.F. Cancio and Associates/Urban Engineers/Proconsult Engine \\
\hline Zone & 3 \\
\hline Latitude & 14.517911 \\
\hline Longitude & 121.051067 \\
\hline Remarks & 0 \\
\hline PDF_File & https://apps.dpwh.gov.ph|IRAP_PHOTOS_GeoTagged|GIS $Z$ \\
\hline Shape & Point \\
\hline
\end{tabular}

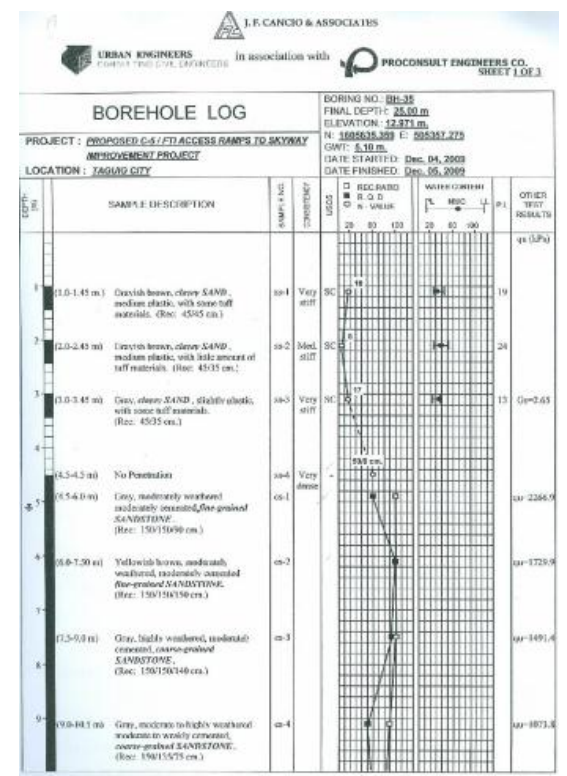

Fig. 4: a) Hyperlink of a Borehole File in ArcGIS b) A Sample Boring Log Hyperlinked to GIS

\section{Probabilistic Seismic Hazard Analysis (PSHA) Contour} Maps

A joint study by the DPWH and JICA in 2013 produced a nationwide contour map entitled the "Generalized Acceleration Response Spectra Development by Probabilistic Seismic Hazard Analysis" was undertaken as a general reference for the Department's Bridge Designers. In this study, the 500-year return period contour maps for the PGA and the Spectral Acceleration at 0.2 seconds and 1 second were taken as layers for this particular assessment.

The PSHA contour maps were drawn at a very large map scale and therefore suffer from scaling generalization particularly in a densely packed region such as the Greater Manila Area. It can, however, serve as the baseline Response Spectra for national bridges, with the DSHA-derived response spectrum as the comparative spectrum. The response spectrum yielding the higher spectral accelerations shall be taken as the governing response spectrum for highly critical long span bridges. Moreover, the PGA's herein presented cannot be used as a criterion for the Hazard Ranking Table since the PSHA contour maps tend to cluster a large area into a single value. Figure 5 shows the 500-year contour maps reflected overlain on the Bridge Inventory of the DPWH.
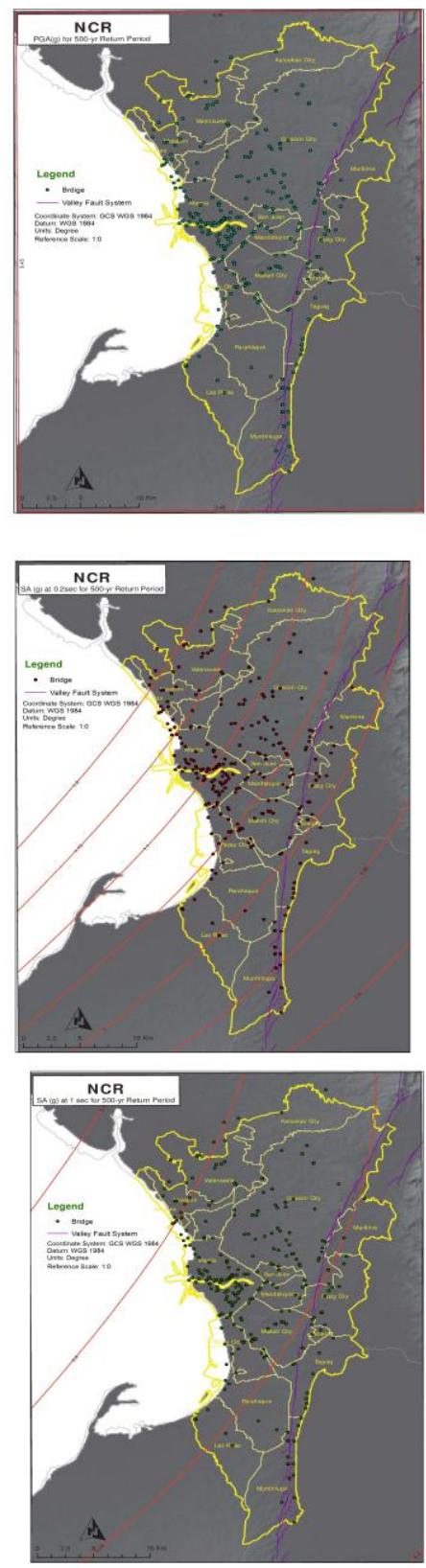

Fig. 5: a) PGA Map at 500-Year Return Period b) Spectral Acceleration 0.2s at 500-Year Return Period c) Spectral Acceleration 1 s at 500-Year Return Period

\section{E. Hazard Ranking Criteria}

In order to make this study more relevant to disaster response, a Hazard Ranking Criteria is herein proposed to identify bridges most susceptible to earthquake damage. As stated in the preceding sections, three criteria will be used to determine the overall ranking. The formula is given below in equation 2 .

$$
H_{B R}=0.5 H_{P G A}+0.3 H_{C}+0.2 H_{L}
$$


In this equation, $H_{B R}$ is the total Hazard Score while $H_{P G A}, H_{C}$, and $H_{L}$ are the hazard components due to PGA by DSHA, Bridge Condition, and Bridge Length respectively. The equations for $H_{P G A}$ is given in equation 3.

$$
H_{P G A}=\left(P G A_{B R} / P G A_{M A X}\right) x 100
$$

The condition statements in RBIA will be used as the basis for $H_{C}$ while the bridge length range will be the basis for $H_{L}$. The values in Table 1 provide the equivalent scores for $H_{C}$ and $H_{L}$.

TABLE I: EQuivaLENT SCORE For $H_{C} \& H_{L}$

\begin{tabular}{cccc}
\hline \hline Bridge Condition & $H_{C}$ & Bridge Length & $H_{L}$ \\
\hline Good & 60 & $\mathrm{~L}<10 \mathrm{~m}$ & 60 \\
Fair & 80 & $10 \mathrm{~m}<\mathrm{L}<30 \mathrm{~m}$ & 80 \\
Poor, Bad, and No & 100 & $\mathrm{~L}>30 \mathrm{~m}$ & 100 \\
Assessment & & &
\end{tabular}

As seen from our PGA Hazard Criteria, the minor differences in PGA are of utmost importance in ranking bridges in relatively close proximity to each other. The highest PGA in the cluster is given the full hazard score while the other PGA's are normalized to this value. On the other hand, the qualitative condition statements in RBIA are simply taken at face value with better qualitative statements receiving 20 hazard scores less than the succeeding condition statement. As per length, bridges between $10 \mathrm{~m}-30 \mathrm{~m}$ are given the middle score of 80 since the bridge cluster's median length is at $12 \mathrm{~m}$. The $30 \mathrm{~m}$ upper limit takes into account the maximum length of bailey bridges; hence bridges longer than $30 \mathrm{~m}$ cannot be replaced with bailey bridges in the immediate response time frame.

\section{SAMPLE RESUltS}

\section{A. Bridge Identification within 5-10 km of the West Valley} Fault

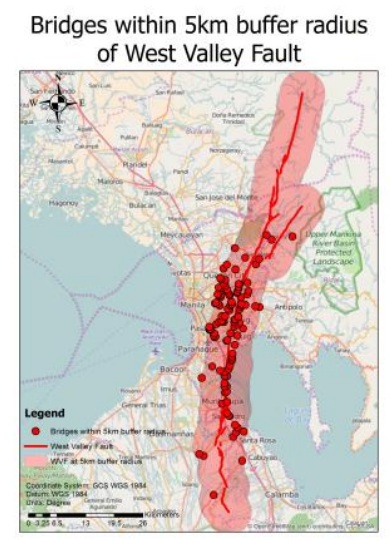

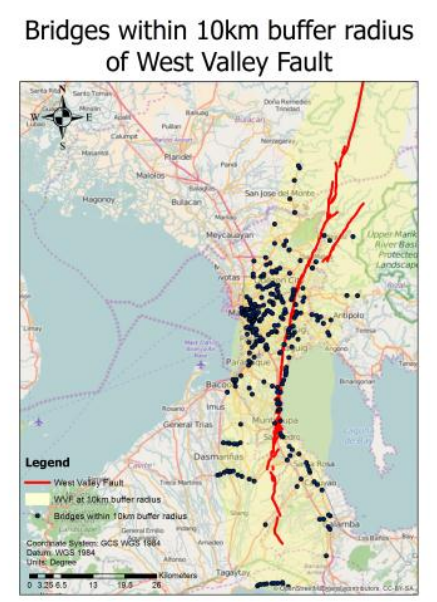

Fig. 6: a) Bridges at 5-km Radius of WVF b) Bridges at 10-km Radius of WVF

\section{B. DHSA and Hazard Ranking}

TABLE II: DHSA AND HAZARD RANKING RESULTS FOR TOP 4 BRIDGES

\begin{tabular}{cccccccc}
\hline \hline Bridge Name & PGA (g) & $H_{P G \text { A }}$ & $\begin{array}{c}\text { Bridge } \\
\text { Condition(m) }\end{array}$ & $H_{C}$ & $\begin{array}{c}\text { Bridge } \\
\text { Length (m) }\end{array}$ & $H_{L}$ & $H_{R R}$ \\
\hline Katipuman/Boni & 0.729 & 97.21 & No Assesment & 10 & 700 & 100 & 98.60 \\
$\quad \begin{array}{l}\text { Serrano } \\
\text { C.P. Garcia Br. }\end{array}$ & 0.743 & 99.09 & Fair & 80 & 262 & 100 & 93.55 \\
Vargas Br. & 0.742 & 98.21 & Fair & 80 & 126 & 100 & 93.10 \\
Katipunan Viaduct & 0.736 & 98.13 & Fair & 80 & 198 & 100 & 93.06 \\
\hline
\end{tabular}

In Table 2, it is evident that the close values of the Hazard Scores is exacerbated by the general condition statements provided by RBIA and the broad categories provided by the authors in terms of length hazards. In this regard, the minute differences in the PGA values will be the deciding factor in the Hazard Ranking. Despite the limitations of the presented ranking criteria, the ease and ubiquity of the data required to do this ranking is seen as a sufficient disaster response criteria for non-structural disaster response (e.g. NDRRMC, Office of Civil Defence etc.)

\section{Response Spectra Comparison}

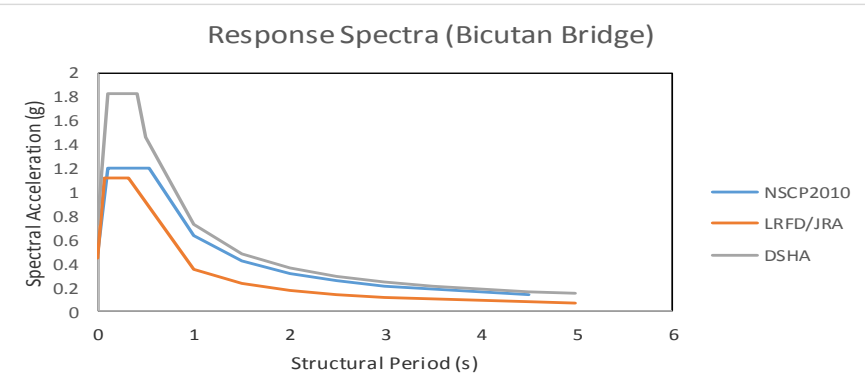

Fig. 7: Comparison of Different Response Spectra using Different Codes

In Figure 7, it can be seen that the uniform design response spectrum produced by DSHA is greater than the one produced by the PSHA 500-year return period by the JRA. The response spectra computation provided by the National Structural Code of the Philippines 2010 provides the median spectra between the two. As provided in the DPWH Design Guidelines, Criteria, and Standards of 2015 Volume 2A, the NSCP, 
JRA/LRFD, and the DSHA response spectra are intended for the design of buildings, bridges, and critical infrastructure respectively (e.g. railways, hospitals etc.)

\section{RECOMMENDATIONS FOR FURTHER RESEARCH AND IMPROVEMENT}

As can be seen from the sample data produced by this analysis, GIS-based seismic hazard mapping is an effective way of identifying and ranking bridge hazards using database integration. The geospatial analysis undertaken can also produce design response spectra for retrofitting or replacement of decrepit national bridges. However, the hazard ranking criteria herein presented will need further refinement to make a representative score of all the hazard factors existent in national bridges (e.g. fractures, wear and tear of bearing pads, seating length etc.) and as well as Operation Classification. However, as of the moment, the RBIA does not take into account the aforementioned parameters since the Department is still in the process of updating the current Bridge Seismic Design Specifications. The Geotechnical database in the Department would need bolstering in number and quality. It is envisioned that collaboration with the field offices can supplement the gaps in the current subsurface data in GIS. As of writing, the authors are preparing an extension of this database to include liquefaction hazards and seismicallyinduced mass wasting of engineered slopes.

\section{ACKNOWLEDGMENT}

The authors would like to thank the Department of Public Works and Highways for enabling us to integrate the databases within the Department in order to conduct this seismic hazard assessment.

\section{REFERENCES}

[1] DPWH Design Guidelines Criteria and Standards Vol. 2A: GeoHazard Assessment, $1^{\text {st }}$ ed., Department of Public Works and Highways, Manila, PH, 2015

[2] Earthquake Impact Reduction Study Vol.1:Final Report, PHIVOLCS et al., Manila, PH, 2004

[3] National Structural Code of the Philippines Vol.1:Buildings Towers, and other Vertical Structures, ASEP, Quezon City, PH, 2010

[4] The Project for Study on Improvement of Bridges through Disaster Mitigating Measures for Large Earthquakes, Final Report Annex-2A., Department of Public Works and Highways, Manila, PH, 2013. 